EMSP Project ID Number 60123

Agreement Number: DE-FG07-97ER 14819

\title{
POTENTIAL MOdUlated INTERCALATION OF ALKALI CATIONS INTO METAL HEXACYANOFERRATE COATED ELECTRODES
}

PROGRESS REPORT: $2 / 18 / 02$

Principal Investigator

Daniel T. Schwartz

University of Washington

Department of Chemical Engineering

Box 351750

Seattle, WA 98195-1750

TEL: 206 685-4815; E-Mail: dts@u.washington.edu

Co-Investigator(s): None

Research Personnel Supported (in part) by Project in Final Year

Graduate students

-Kavita M. Jeerage

-William A. Steen

-Haixia Dai

Postdoctorate

-Qiuming Yu

\section{Specific DOE Problems Addressed by Project}

The separation of radiocesium from other cations has important cost and safety implications for the processing of various cesium contaminated wastes forms such as basin waters and sludges (e.g., at Hanford and Savannah River sites), as well as groundwater and more acidic tank wastes (e.g. at the Idaho Site). The key feature of these sites being their cesium contamination in a moderate to low $\mathrm{pH}$ aqueous solvent.

\section{Overall Research Objectives}

Nickle hexacyanoferrate is a polynuclear inorganic ion intercalation material that loads (intercalates) and elutes (deintercalates) alkali cations from its structure when electrochemically reduced and oxidized, respectively. Nickel hexacyanoferrrate (NiHCF) is known to preferentially intercalate cesium over all other alkali cations, thus providing a basis for a separation scheme that can tackle DOE's radiocesium contamination problem. This program studied fundamental issues in alkali cation intercalation and deintercalation in nickel hexacyanoferrate compounds, with the 
goal of (1) quantifying the ion exchange selectivity properties for cation mixtures, (2) enhancing ion exchange capacities, and (3) and understanding the electrochemically-switched ion exchange process (ESIX).

\section{Year 4 Progress Report and Implications}

The final year (a no-cost extension) of this project has been extremely productive. Eight peer reviewed publications have appeared, are in press, or are at some state of the editorial process (see below). Below, we separately address our progress toward each of the goals of this research.

Most of our effort has been directed toward goal (1), where the overriding question has been, "what materials do we make by electrodepositon, and how do their properties depend on stoichiometry and structure?" Publications, (1)-(5), (7), and (8) have tackled the issue by developing appropriate measurement techniques that can get at properties and structure of thin nickel hexacyanoferrate films. A combined electrochemical, Raman spectroscopy, and energy dispersive x-ray spectroscopy method has been developed for analyzing the quantity and type of ion loaded into NiHCF films. In journal article (2), (3), and (5) cited below, we describe the methodology and show the range over which this technique can be used to quantify separation factors in NiHCF coated electrodes. We find that the distribution coefficient for NiHCF coated electrodes can exceed $3 \times 10^{4} \mathrm{ml} / \mathrm{g}$ in a solution of $10^{-6} \mathrm{M} \mathrm{Cs}^{+}$with excess sodium nitrate $(1 \mathrm{M}$ $\mathrm{Na}^{+}$). However, cited paper (5) shows that the ion selectivity is strongly dependent on the oxidation state of nickel hexacyanoferrate, where the highest cesium selectivities are displayed by the oxidized matrix and the lowest selectivities are found in the reduced matrix. The origin of the charge-density dependence is $\mathrm{Cs}^{+}-\mathrm{Cs}^{+}$repulsion in the reduced (fully loaded) matrix. These experimental results are complemented by molecular dynamic simulations (paper (4)), where we explore the role of solid structure on the nature of ion and solvent intercalation. Together, these papers point to the role of size exclusion in nickel hexacyanoferrate, with more ideal structurefunction relationships exisiting in nickel hexacyanoferrate thin films that posses a high density of feroocyanide defects in the solid.

For goal (2), all of the papers presented below (except (1)) used the cathodic deposition of nickel hexacyanoferrate on noble metal electrodes as a high capacity means of synthesis. In the this approach, NiHCF is deposited cathodically by cycling a platinum electrode between +850 and $0 \mathrm{mV}$ vs. SCE at a scan rate of $25 \mathrm{mV} / \mathrm{S}$ in freshly prepared solution of $4 \mathrm{mM} \mathrm{NiSO}_{4}, 4 \mathrm{mM}$ $\mathrm{K}_{4} \mathrm{Fe}(\mathrm{CN})_{6}$ and $500 \mathrm{mM} \mathrm{Na}_{2} \mathrm{SO}_{4}$. The resulting thin films can routinely be produced with ion intercalation capacities exceeding $8 \mathrm{mC} / \mathrm{cm}^{2}$. Previously, our anodic deposition scheme (used in paper (1)) produced a typical capacity of $3 \mathrm{mC} / \mathrm{cm}^{2}$, so cathodic deposition represents a roughly 3 fold improvement in capacity.

Our effort to address Goal (3) has been to develop macroscopic batch contacting models for the ESIX process. This work is represented by paper (6) below. The model we've developed takes into account the electrochemical nature of the experiment, and all physical processes that are involved in an equilibrium process (in this case, rate parameters are ignored). We show that ESIX has the possibility of recovering a high fraction of the target ion from a binary mixture, and concentrate it into a product stream (something conventional ion exchange cannot do), but to do 
so requires a combination of selectivity and ion elution efficiency that has not yet been achieved, but is clearly possible.

\section{Information Access}

(1) D.T. Schwartz and S.M. Haight, Transport and chemistry at electroactive interfaces studied using line-imaging Raman spectroscopy, Colloid Surf. A 174, 209-219 (2000).

(2) K.M. Jeerage and D.T. Schwartz, Characterization of cathodically deposited nickel hexacyanoferrate for electrochemically switched ion exchange, Sep. Sci Tech. 35, 2375-92 (2000).

(3) K.M. Jeerage, W.A. Steen, and D.T. Schwartz, Correlating nanostructure with ion intercalation in electrodeposited nickel hexacyanoferrate thin films, Chem. Mat. 14, 530-535 (2002).

(4) Q. Yu, W.A. Steen, K.M. Jeerage, S. Jiang, and D.T. Schwartz, Structure-dependent solvent and ion intercalation in reduced and oxidized nickel hexacyanoferrates, J. Electrochem. Soc., in print (2002).

(5) K.M. Jeerage, W.A. Steen, and D.T. Schwartz, Charge-density-dependent partitioning of $\mathrm{Cs}^{+}$ and $\mathrm{K}+$ into nickel hexacyanoferrate matrices, Langmuir. accepted (2002).

(6) K.M. Jeerage and D.T. Schwartz, An equilibrium stage model for electrochemically-switched ion exchange separations, Ind. Eng Chem. Res. submitted (2001).

(7) W.A. Steen, K.M. Jeerage, and D.T. Schwartz, Spectroscopic determination of nickel hexacyanoferrate oxidation state, Appl. Spec., submitted (2002)

(8) W.A. Steen, Q. Yu, and D.T. Schwartz, Structure of electrodeposited nickel hexacyanoferrate by $\mathrm{x}$-ray diffraction and extended $\mathrm{x}$-ray absorption fine-structure, $J$. Electrochem. Soc., in preparation (2002). 